\title{
Effectiveness of isolated compound from Aloe barbadensis Miller and its formulated ointment against bacteria and fungi
}

\begin{abstract}
Ethnomedicinally, the family Liliaceae is prominent in controlling skin, wound and fungal infections. A carboxylic fatty acid derivative has been isolated from Aloe vera leaves and its structure was elucidated on the basis of NMR and FT-IR analysis. The compound was formulated as ointment with the aid of polymer based delivery agent. The ointment and the uncontaminated fatty acid have been scrutinized aimed at their anti-infectious potential. Individually, the pure compound and the formulated ointment exhibited growth inhibitory activity against Pseudomonas aeruginosa, Escherichia coli, Staphylococcus aureus, Klebsiella pneumoniae, Candida albicans and Talaromyces flavus. Minimum inhibitory concentration (MIC) values were found to be appreciably low, ranging between 0.30 and $2.50 \mathrm{mg} / \mathrm{ml}$. The formulated ointment displayed highly significant inhibitory activities against all six pathogens compared to the unformulated compound. The MIC values of the ointment ranged between 0.08 and $1.25 \mathrm{mg} / \mathrm{g}$. The in vitro antibiotic activity studies discovered that, both the pure compound and the formulated ointment showed potency against the selected multi-resistant microorganisms tested in the current work. These findings suggest that the isolated carboxylic acid derivative may be beneficial in the discovery of antibiotics highly potent against drug-resistant pathogens. Furthermore, it may add to the improvement of preservatives in the food industry. Lastly, it could be considered as new source of natural antibiotics in the pharmaceutical industry.
\end{abstract}

Keywords: Aloe, minimum inhibitory concentration, formulated, microorganism
Volume 8 Issue 2 - 2021

\author{
Martin Ntiamoah Donkor,' Ngmenpone \\ Kuubabongnaa, ${ }^{2}$ Addai-Mensah Donkor ${ }^{\prime}$ \\ 'Department of Applied Chemistry and Biochemistry, C. K. \\ Tedam University of Technology and Applied Sciences, Ghana \\ ${ }^{2}$ Department of Applied Chemistry and Biochemistry, University \\ for Development Studies, Ghana
}

Correspondence: Martin Ntiamoah Donkor, Department of Applied Chemistry and Biochemistry, Faculty of Applied Sciences, C. K. Tedam University of Technology and Applied Sciences, Navrongo, Ghana, Email mdonkor@cktutas.edu.gh

Received: March 12, 202I | Published: April 02, 2021
Abbreviations: DMSO, dimethyl sulfoxide; $\mathrm{MBC}$, minimum bactericidal concentration; MFC, minimum fungicidal concentration; MIC, minimum inhibitory concentration

\section{Introduction}

Microbial infections are among the leading causes of morbidity and mortality globally. Several antibiotics have been developed over the years; however, most of these drugs have been ineffective because of the emergence of multidrug resistant pathogens and appearance of strains with reduced susceptibility to antibiotics. ${ }^{1-3}$ This has been a major source of concern to health professionals, scientists and other stakeholders. The problem has been attributed to nonprescribed usage of saleable antimicrobial medications frequently used in the management of infectious dieseases. ${ }^{4,5}$ There is the need to continuously search and design new molecular candidates that have broad spectrum effect, easily accessible, more effective and able to withstand microbial resistance. Natural products, especially, of herbal origin, have been utilized in treating infectious and non-infectious diseases, a practice dating back to prehistory.

Currently, all over the world, far-reaching research works remain in progress concerning beneficial uses of herbal florae. They are perceived to have lesser side effects, unlimited abundance, easily reachable, affordable and are understood to increase excellence of lifespan. Plants encompass several structurally distinctive bioactive compounds that are used either directly as precursors or as lead compounds in the pharmaceutical industry. ${ }^{6}$ For example, Piper species, known to be aromatic plants, are considered rich in essential oils, which are reported to be located in their fruits, seeds, leaves, branches, roots and stems. They could be found in potential uses as natural antioxidants and antimicrobial agents in food preservation. The phytochemicals and essential oils of Piper species have been reported to exhibit strong antioxidant activity, in comparison with synthetic antioxidants, and demonstrated antibacterial and antifungal activities against human pathogens. ${ }^{7}$

Aloe barbadensis Miller (Aloe vera L.), a member of Liliaceae family, is one of the over 360 species of the Aloe plant, with the common name "True aloe" or "Curaçao aloe". 8 The whole leaf extract, as well as the two primary components (the gel and the latex or exudates) of the leaf, have been used for various reasons in traditional medicine. The plant is known to be a natural cleanser, potent in penetrating tissues, relieving ache concomitant with joints and muscles, bactericidal, a strong antibiotic, virucidal, fungicidal, and anti-inflammatory. ${ }^{9-11}$ Aloe barbadensis Miller gel is used in traditional settings where it is administered topically to treat sores, minor burns and skin irritations. Additionally, it has been used internally for the management of constipation, coughs, ulcers, diabetes, headaches, arthritis and immune-system deficiencies. ${ }^{10,12}$

Even though there has been a quantity of compounds isolated from the plant, most of its pharmacological prospects are focused on the gel..$^{8,11,13-15}$ Thus, in the present study, we isolated a lipid derivative from the whole leaf extract of Aloe barbadensis Miller for the first time in research, and explored the activity of both the pure compound and the polymer-based ointment, in vitro, alongside six designated clinical isolates of essential pathogens very much linked with outbreak of diseases and antibiotic resistance phenomenon. 


\section{Materials and methods}

\section{Collection and preparation of plant material}

Well-preserved sample of powdered dried leaves processed from Aloe barbadensis Miller plant, which had previously been validated by a plant taxonomist with receipt sampling (number: $\mathrm{SH} 722$ ), was used for this current research work. ${ }^{16}$

\section{Preparation of crude extracts}

Pulverized Aloe barbadensis Miller leaf material (1.50 kg) was soaked in absolute ethanol (5.00 1), designed for three days around approximately $25^{\circ} \mathrm{C}$. The blend was intermittently mixed thoroughly in anticipation of enriching the removal of the phytoconstituents in the mixture. Resulting assortment was sifted after equilibration and an oil residue recovered through application of a rotary evaporator under water bath at $40^{\circ} \mathrm{C}$. The quantity was estimated at approximately $165.40 \mathrm{~g}(11.00 \% \mathrm{w} / \mathrm{w})$.

\section{Isolation of compound G}

The crude plant material $(52.00 \mathrm{~g})$ was distributed between normal hexane and aqueous solvent $(1: 1)$. The hexane fraction $(5.50 \mathrm{~g})$ was eluted through chromatography process on silica gel $\mathrm{H}(60-120 \mu \mathrm{m}$ mesh size) and fractionated via solvents of variable polarity of ethyl acetate/hexane $(0-100 \%)$ to provide 51 fractions. Fractions $31-41$ (green colored fractions) were recombined to give $338.90 \mathrm{mg}$ and further subjected to column chromatography over silica gel $\mathrm{H}$ eluted with $\mathrm{CHCH}_{3}$ followed by $\mathrm{CH}_{3} \mathrm{OH} / \mathrm{CHCl}_{3}$ (5:95) and $\mathrm{CH}_{3} \mathrm{OH} / \mathrm{CHCl}_{3}$ (10:90) to provide 13 fractions. Fractions 6-10 were recombined, totaling $57.70 \mathrm{mg}$ and further purified using preparative thin layer chromatography (silica gel F254 60 coated on glass plates $20 \mathrm{~cm} \times 20$ $\mathrm{cm}$ ) to afford compound $\mathrm{G}$ (Figure 1), a total mass of $49.10 \mathrm{mg}\left(\mathrm{R}_{\mathrm{f}}\right.$ 0.67 in $10 \% \mathrm{CH}_{3} \mathrm{OH} / \mathrm{CHCl}_{3}$ ).

\section{Spectroscopic characterization of compound G}

The characterization of the isolated compound was performed utilizing the following: Beckman DU-7400 and Perkin Elmer FTIR spectrometers were respectively applied in recording UV and FT-IR spectra. Proton NMR (500 MHz) and carbon-13 NMR (125 $\mathrm{MHz}$ ) spectra were recorded on a Bruker AMX500 instrument with chemical shift data recounted in parts per million ( $\mathrm{ppm}$ ) relative to the solvent used with field gradient BBI (inverse) probe, analogous to reported data. ${ }^{16}$

\section{Reconstitution of compound G}

The isolated Compound $\mathrm{G}$, was reconstituted in $1 \mathrm{ml}$ dimethyl sulfoxide (DMSO, $99.99 \%$ ) diluted to a concentration of $0.5 \%(\mathrm{v} / \mathrm{v})$, and serially diluted to obtain the desired concentrations of $20,10,2.5$, $1.25,0.63,0.32,0.16,0.08$ and $0.04 \mathrm{mg} / \mathrm{ml}$. Portions were kept at $-80^{\circ} \mathrm{C}$ in anticipation for further use.

\section{Ointment formulation of compound G}

Formulation of compound $\mathrm{G}$ ointment using polyethylene glycol (PEG) as the ointment base, thus, PEG 4000 (BDH Chemical Ltd, England) and PEG 400 (ReAgent, UK), were employed to formulate the ointment as described elsewhere. ${ }^{16}$

\section{Biological studies}

\section{Bacterial and fungal isolates}

A total of four clinical bacterial and two fungal specimens from sterile wounds were isolated in March 2017 from the Microbiology Laboratory, Tamale Teaching Hospital, Northern Region of Ghana. Bacterial species were Escherichia coli, Staphylococcus aureus, Pseudomonas aeruginosa and Klebsiella pneumoniae, whereas Candida albicans and Talaromyces flavus were the fungal species. Bacterial isolates were upheld between 2 and $8^{\circ} \mathrm{C}$ on nutrient broth and the fungal isolates were maintained at $4{ }^{\circ} \mathrm{C}$ on potato dextrose agar. ${ }^{16}$ These isolates were sent to the Microbiology Laboratory, Department of Applied Biology, University for Development Studies, Navrongo Campus, aimed at safeguarding, until use in the ensuing microbiological studies.

\section{Correlation of in vitro efficacy}

A technique reported by Donkor et al., ${ }^{17}$ was utilized for the agar diffusion assay. Plates comprising equipped Mueller-Hinton were correspondingly labeled. Broth culture, $0.01 \mathrm{ml}$, of each microorganism was aseptically injected onto the plates and spread evenly to cover the entire periphery using a sterilized glass rod. Both the test compound and formulated ointment of $20,10,5$ and $2.5 \mathrm{mg} /$ $\mathrm{ml}$, and $20,10,5$, and $2.5 \mathrm{mg} / \mathrm{g}$ concentrations respectively, were hosted into their corresponding wells of $5 \mathrm{~mm}$ diameter. Each was permitted to stand for about $1 \mathrm{~h}$ for pre-diffusion before incubating at $37^{\circ} \mathrm{C}$ for $24 \mathrm{~h}$. Subsequently, zones of inhibition were measured in millimeters $(\mathrm{mm})$ for both the pure compound and the ointment.

\section{Evaluation of antifungal activity}

The process reported previously was explored to conduct antifungal activity for both the isolated compound and the formulated ointment. ${ }^{16,18}$

\section{Inoculum planning for minimum inhibitory concentration (MIC) and minimum bactericidal concentration (MBC)}

Preparation of inoculum for the MIC and MBC assessment was done using research report. ${ }^{18}$ This was initiated by taking a minimum of three to five well isolated colonies of equivalent morphology of test organism from agar plate culture. A sterilized loop was applied to touch the topmost of each colony and the ring transferred into a conduit comprising $5 \mathrm{ml}$ of standard saline and subsequently vortexed. The broth culture was incubated at $37^{\circ} \mathrm{C}$ and monitored for $4 \mathrm{~h}$ until it reached the turbidity of $0.5 \mathrm{McF}$ arland standards $\left(1.5 \times 10^{8} \mathrm{cfu} /\right.$ $\mathrm{ml}$ ), whilst inoculum turbidity quantification was achieved through visualization by the unaided eye.

\section{Minimum bactericidal (MBC) and minimum inhibitory concentration (MIC) determination}

Agar well diffusion and tube diffusion methods described by Donkor et al., ${ }^{17}$ were employed for the evaluation of MICs and MBCs for both the pure compound and the ointment.

\section{Minimum fungicidal concentration (MFC)}

The process described elsewhere ${ }^{18}$ was utilized to probe for the minimum fungicidal concentration (MFC). Fluconazole (Sigma) was designated as affirmative and DMSO (approximately $100 \%$ purity) as negative control. All experiments were executed in triplicates and duplicated to check for the extent of consistency.

\section{Statistical analysis}

All values for the zones of inhibition expressed as means \pm standard deviation were scrutinized via One-way ANOVA followed by Tukey 
multiple comparison test. $\mathrm{P}<0.05$ was considered as significant GraphPad Prism $5^{\circledR}$ (GraphPad Software, version 5) was employed for the statistical enquiry.

\section{Results and discussion}

\section{Isolation and identification of compound G}

Chromatography and purification of ethanol leaf extract from Aloe barbadensis Miller has afforded a pure compound and the structure has been elucidated as hexadecanoic acid;(9Z,12Z)-octadeca-9,12 dienoic acid;octadecanoic acid; (9Z,12Z,15Z)-octadeca-9,12,15 trienoic acid;(Z)-octadec-9-enoic acid. To the best of our knowledge, this is the first occasion that this particular carboxylic fatty acid derivative has been isolated from the genus Aloe. The structure of the isolated fatty acid, compound $\mathrm{G}$ (Figure 1) was found to be consistent with that of olive oil on the foundation of its spectral data compared with one reported in literature..$^{19}$ FT-IR spectra of the oil in the region between 4000 and $550 \mathrm{~cm}^{-1}$ is shown in Figure 2. The weak broad absorption band observed at $3362 \mathrm{~cm}^{-1}$ corresponds to polymeric $\mathrm{O}-\mathrm{H}$ stretching modes. ${ }^{20}$ Absorption bands observed at 2922 and $2852 \mathrm{~cm}^{-1}$ related to asymmetric and symmetric vibration of the $\mathrm{CH}_{2}$ stretch, respectively. ${ }^{21}$ The band at $1742 \mathrm{~cm}^{-1}$ is due to the $\mathrm{C}=\mathrm{O}$ stretch of triglyceride ester linkage, ${ }^{22}$ while the small band at $1652 \mathrm{~cm}^{-1}$ is due to the absorption of $\mathrm{C}=\mathrm{C}$ cis stretching. The $\mathrm{CH}$ absorption of bending vibrations $\mathrm{CH}_{2}$ and $\mathrm{CH}_{3}$ bands can be noticeably seen in the region of 1463 and $1377 \mathrm{~cm}^{-1}$ respectively. The band at $1164 \mathrm{~cm}^{-1}$ is due to the absorption of $\mathrm{C}-\mathrm{O}$ ester bonds, whereas the band at $720 \mathrm{~cm}^{-1}$ is as a result of $\mathrm{CH}_{2}$ rocking vibration..$^{23}$ The chemical shifts $(\delta)$ and assignment of the main resonances in the $1 \mathrm{H}$ NMR spectrum (Figure 3 ) are shown in Table 1, whiles Table 2 represents that of 13C NMR spectrum (Figure 4).<smiles>CCC=CCC=CCCC(=O)OC(C)C(C)OC(=O)CC</smiles>

Figure I Structure of compound G.

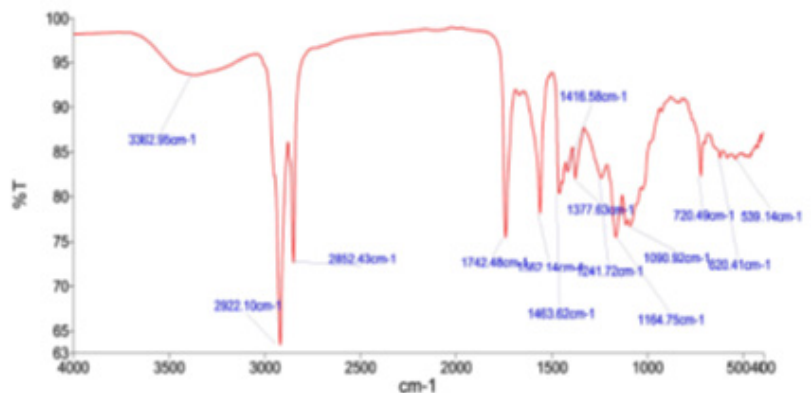

Figure 2 FT-IR Spectrum of compound G.

Previous research indicates Oleanolic acid extraction and characterization from different plants. ${ }^{24}$ The extraction techniques employed included, ultrasound assisted extraction, soxhlet extraction and microwave assisted extraction. The research group further reported that the compound exhibited anti-infective potency against Listeria monocytogenes, Enterococcus faecalis and Enterococcus faecium by disrupting their cell membrane. Additionally, there was moderate activity of Oleanolic acid against $S$. aureus and Bacillus thuringiensis at $62.5 \mu \mathrm{g} / \mathrm{ml}$ minimum inhibitory concentration. Interestingly, 3-epioleanolic acid showed a stronger antibacterial action with MIC ranging from 0.9 to $7.9 \mu \mathrm{g} / \mathrm{ml}$.

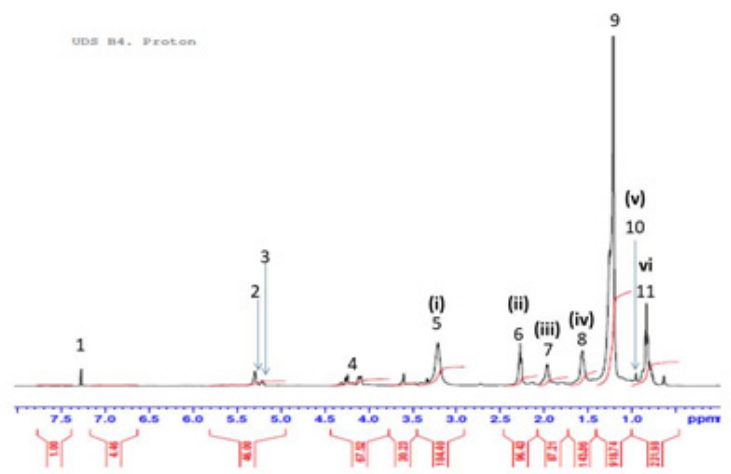

Figure 3 'H NMR of Compound G.

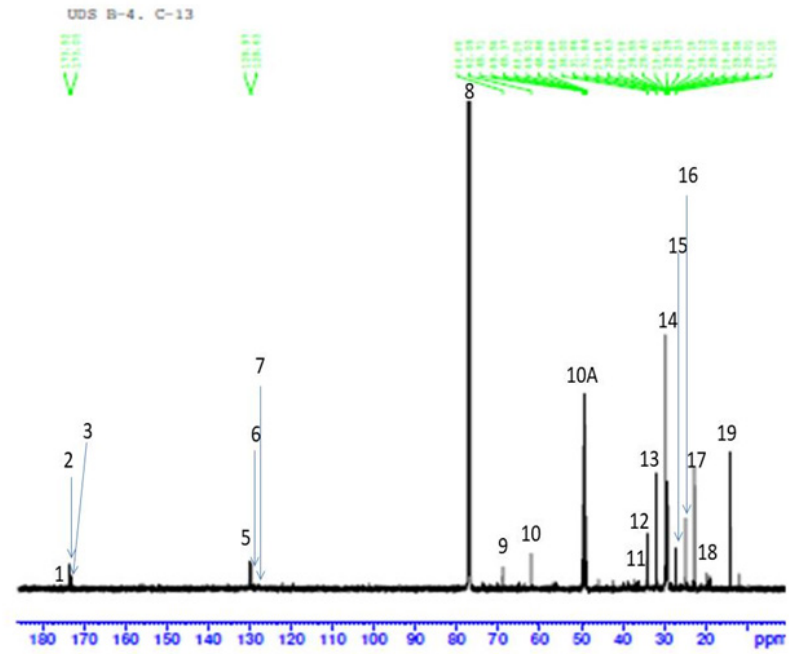

Figure $4{ }^{13} \mathrm{C}$ NMR of Compound G.

\section{Effect of isolated compound on selected microorganisms}

The isolated compound was tested for its inhibitory growth activity against six selected isolated clinical pathogens. Organic acids are distinguished as excellent candidates for preventing microbial contamination, and their anti-infectious potential has been attributed to the capacity to readjust from un-dissociated to dissociated form, contingent on the $\mathrm{pH}$ of the environment, ${ }^{25}$ making them effective antimicrobial agents. Notably, propionate of sodium and calcium preclude decomposition by preventing the growth of microorganisms, hence, employed against spoilage in food products. Carboxylic acids again are reported to play substantial functions in therapeutic application. The presence of organic acids, as intermediary metabolites of key cellular components, has been related with superfluous and numerous fluids of the biological system, which are connected to the incidence of degenerative diseases. ${ }^{26,27}$

The difficulty for bacteria to mutate to become resistant to antimicrobial lipids as a result of the characteristics features of lipids 
have been reported. ${ }^{28}$ The group reported further that a 12 carbon-long chain compound, lauric acid, had the most potent activity to prevent growth of Gram-positive bacteria, whilst the monoglyceride analogue, showed even stronger inhibitory action. Investigated application of diverse experimental methods have detected that the mechanism(s) of antibacterial activity of fatty acids primarily aim at bacterial cell membrane and interfere with crucial processes associated with cellular defense as well as function. It has been established that, two of the most vital processes amongst others involving bacterial cell membranes, are the electron transport chain and oxidative phosphorylation, which are crucial bacterial cells energy production. The two processes are reported to be interrelated, and fatty acids could alter the membrane integrity in addition to meddling with oxidative phosphorylation by decreasing the membrane potential and proton gradient. Moreover, fatty acids are reported to directly impede membrane enzymes, for example, glucosyltransferase, ostensibly as a result of comparable molecular structures with known small molecule inhibitors. ${ }^{29}$

Table I Chemical shifts $(\delta)$ and assignment of the main resonances in the IH NMR spectrum of

\begin{tabular}{|c|c|c|c|c|}
\hline \multirow[t]{2}{*}{ Peak } & & \multirow[t]{2}{*}{$\delta(\mathrm{ppm})$} & \multicolumn{2}{|l|}{ Assignment } \\
\hline & & & Proton & Compound \\
\hline 1 & & 7.26 & $\mathrm{CHCl}_{3}$ & Chloroform (solvent) \\
\hline 2 & & 5.29 & $\mathrm{CH}=\mathrm{CH}$ & All unsaturated fatty acids \\
\hline 3 & & 5.15 & CHOCOR & Glycerol (triacylglycerols) \\
\hline 4 & & 4.19 & $\mathrm{CH}_{2} \mathrm{OCOR}$ & Glycerol (triacylglycerols) \\
\hline 5 & (i) & 2.76 & $\mathrm{CH}=\mathrm{CHCH}_{2} \mathrm{CH}=\mathrm{CH}$ & Linoleyl and linolenyl \\
\hline 6 & (ii) & 2.2 & $\mathrm{CH}_{2} \mathrm{COOH}$ & All acyl chains \\
\hline 7 & (iii) & 2.02 & $\mathrm{CH}_{2} \mathrm{CH} \times \mathrm{CH}$ & All unsaturated fatty acids \\
\hline 8 & (iv) & 1.6 & $\mathrm{CH}_{2} \mathrm{CH}_{2} \mathrm{COOH}$ & All acyl chains \\
\hline 9 & & 1.2 & $\left(\mathrm{CH}_{2}\right) \mathrm{n}$ & All acyl chains \\
\hline 10 & (v) & 0.95 & $\mathrm{CH}_{2} \mathrm{CH}_{2} \mathrm{CH}_{2} \mathrm{CH}_{3}$ & Linolenyl \\
\hline 11 & (vi) & 0.85 & $\mathrm{CH}=\mathrm{CHCH}_{2} \mathrm{CH}_{3}$ & All acids except linolenyl \\
\hline
\end{tabular}

Compound G

Table 2 Chemical shifts $(\delta)$ and assignment of the main resonances in the ${ }^{13} \mathrm{C}$ NMR spectrum of Compound G

\begin{tabular}{|c|c|c|c|}
\hline Peak & $\delta($ ppm) & Assignment & \\
\hline & & Carbon & Compound \\
\hline 1 & $174-176$ & C-I & Free fatty acids \\
\hline 2 & 173.26 & C-I, sn $-1,3$ & Triacylglycerols \\
\hline 3 & $|72.8|$ & $C-1, s n-2$ & Triacylglycerols \\
\hline 4 & 129.98 & $C-10$ & Oleyl \\
\hline 5 & 129.67 & C-9 & Oleyl \\
\hline 6 & 128.06 & $C-10$ & Linoleyl \\
\hline 7 & 127.86 & $C-12$ & Linoleyl \\
\hline 8 & 77.01 & $\mathrm{CDCl}_{3}$ & (Solvent) \\
\hline 9 & 68.92 & $\mathrm{CHO}-$, sn -2 & Triacylglycerols \\
\hline 10 & 62.18 & $\mathrm{CH}_{2} \mathrm{O}-, \mathrm{sn}-\mathrm{I}, 3$ & Triacylglycerols \\
\hline $10 \mathrm{~A}$ & 49.95 & $\mathrm{RCH}_{2} \mathrm{O}-$ & \\
\hline 11 & 34.18 & $C-2, s n-2$ & All acyl chains \\
\hline 12 & 34.02 & $C-2, s n-1,3$ & All acyl chains \\
\hline 13 & 31.88 & ०3 & Sat., n É 9 and n É 6 acids \\
\hline 14 & $29.1-29.8$ & $\left(\mathrm{CH}_{2}\right) \mathrm{n}$ & All acyl chains \\
\hline 15 & 27.16 & Allylic : C-8-C-II & leyl, C-8-C-I 4 linoleyl \\
\hline 16 & 25.81 & Diallylic : C-II linc & yl, C-I I-C- I 4 linolenyl \\
\hline 17 & 24.84 & $\mathrm{C} 3$ & All acyl chains \\
\hline 18 & 22.65 & .2 & All acyl chains \\
\hline 19 & 14.15 & ol $\left(-\mathrm{CH}_{3}\right)$ & All acyl chains \\
\hline
\end{tabular}

Gram-negative bacteria, namely, E. coli, $K$. pneumoniae, $P$. aeruginosa, and also one Gram-positive bacterium, $S$. aureus were selected for this research. For the fungal isolates, a yeast (C. albicans) and a mold (T. flavus) were explored in this study. The pure compound $\mathrm{G}$ displayed variable extent of antimicrobial activity towards all the test organisms. Susceptibility test results revealed inhibition ranging from 12.5 to $5.4 \mathrm{~mm}$ for all the selected microorganisms at varying concentrations of 20 to $2.5 \mathrm{mg} / \mathrm{ml}$ correspondingly, with the exception of C. albicans, which showed no sensitivity at $2.5 \mathrm{mg} / \mathrm{ml}$. Observation of the results further shown that the potency of the compound against all the test microorganisms was dose dependent with increased activity as concentration increased (Figure 5). Chloramphenicol, the standard antibacterial drug, showed significantly higher activity $(\mathrm{P}<$ 0.05 ) compared with the compound at all concentrations used in this study. Interestingly, the compound displayed higher activity, which was significant $(\mathrm{P}<0.05)$ against the two fungi at concentrations of 20 , 10 and $5 \mathrm{mg} / \mathrm{ml}$ compared with fluconazole, the standard antifungal drug, specific concentration of $10 \mu \mathrm{g} / \mathrm{ml}$. There was no activity recorded for the negative control $(99.99 \%$ DMSO, concentration of $5 \%, \mathrm{v} / \mathrm{v}$ ). The minimum inhibitory concentration (MIC) and the minimum bactericidal/fungicidal concentrations (MBC/MFC) were used to evaluate the bio-efficacy of the compound on the test organisms. In the present investigation, the compound exhibited appreciably low MIC values ranging from 0.32 to $2.5 \mathrm{mg} / \mathrm{ml}$ (Table 3). Low MIC values of antimicrobials have been associated with high efficacy, whiles high values may indicate low efficacy of antimicrobial agents. ${ }^{30}$ The least MIC value was found to associate with the Gram positive bacterium, $S$. aureus. Gram-negative bacteria are found to be more resistant due to high lipoprotein and lipopolysaccharides content in their cell structure. ${ }^{31}$ The MBC and MFC for the isolated compound were, however, undetected up to a concentration of $40 \mathrm{mg} / \mathrm{ml}$. 


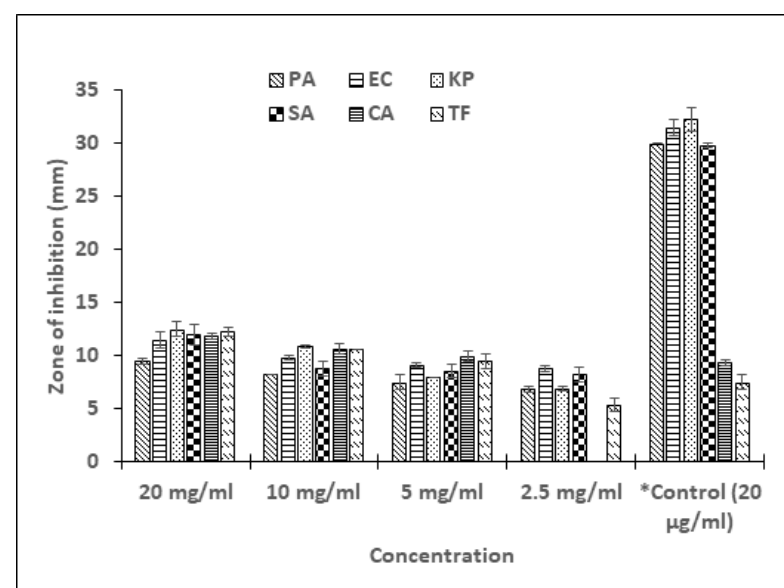

Figure 5 Growth inhibition activity of Compound $\mathrm{G}$ alone on test bacteria and fungi.

$\mathrm{PA}, P$. aeruginosa; $\mathrm{EC}=\mathrm{E}$. coli; KP, K. pneumoniae; $\mathrm{SA}, \mathrm{S}$. aureus; $\mathrm{CA}=\mathrm{C}$. albicans; TV, T. flavus; *Control, Chloramphenicol; positive control for bacteria; Fluconazole, positive control for fungi.

Table 3 MIC and MBC/MFC of compound G and PEG-compound G ointment

\begin{tabular}{lllll}
\hline & \multicolumn{2}{l}{ Compound G } & \multicolumn{2}{l}{$\begin{array}{l}\text { PEG-Compound G } \\
\text { ointment }\end{array}$} \\
\hline Test organism & MIC $(\mathrm{mg} / \mathrm{ml})$ & MBC/MFC & MIC $(\mathrm{mg} / \mathrm{g})$ & MBC/MFC \\
\hline P. aeruginosa & 2.5 & UD & 0.08 & UD \\
E. coli & 1.25 & UD & 0.63 & UD \\
K. pneumoniae & 2.5 & UD & 1.25 & UD \\
S. aureus & 0.3 & UD & 0.63 & UD \\
C. albicans & 2.5 & UD & 1.25 & UD \\
T. flavus & 2.5 & UD & 0.16 & UD \\
\hline
\end{tabular}

MIC, minimum inhibitory concentration; $M B C$, minimum bactericidal concentration; MFC, minimum fungicidal concentration; PEG, polyethylene glycol; UD, undetected detected up to a concentration of $40 \mathrm{mg} / \mathrm{g}$.

Ergosterol serves as a bioregulator of membrane fluidity and asymmetry and consequently of membrane integrity in fungal cells. ${ }^{32}$ Azole antifungals are reported to target the ergosterol biosynthetic pathway. Ergosterol is an important component of the fungal cell membrane; disruption of its synthesis allows accumulation of $14 \alpha$-methyl sterols, which alters membrane stability, permeability, and the action of membrane-bound enzymes. ${ }^{33,34} \mathrm{~A}$ prevalent resistance mechanism is the activation of membrane-associated efflux pumps, which recognize diverse chemicals enabling multidrug resistance. In fungi, two different drug efflux systems modulate azole resistance, the ATP-binding cassette superfamily and the major facilitator superfamily. ${ }^{35}$ Antifungal resistance of azole drugs reported to target cell membranes has been stated to emerge through multiple mechanisms including overexpression or alteration of the drug target, up-regulation of drug transporters, or cellular changes that reduce drug toxicity or enable tolerance of drug-induced stress. Polyene resistance is described generally to involve depletion of the target ergosterol attributable to loss-of-function mutations in ergosterol biosynthetic genes. ${ }^{35}$

Drug action often requires import of the drug into the cell to reach the drug target. Some antifungal agents use specific permeases to enter cells. For example, 5-fluorocytosine uses permeases to enter $C$. albicans cells. ${ }^{36}$ Recently, it was shown that the antifungal peptide histatin 5, as well as amine-containing substrates use the Dur31 permease in C. albicans. ${ }^{37}$ Agents like doxycycline enhance the action of azoles like fluconazole presumably by depleting heme-associated iron. ${ }^{38}$ Amino acid substitutions in the drug target that inhibit drug binding are also reported to be a common azole-resistance mechanism in Candida. ${ }^{39}$

Research reports indicate that molds which are able to survive at $85{ }^{\circ} \mathrm{C}$ for $4.5 \mathrm{~min}$, low oxygen tension, low $\mathrm{pH}(3.0-4.5)$ and produce pectinolytic enzymes, have an influence on juice stability. Some notable species mentioned are Byssochlamys fulva, B. nivea, Neosartorya fischeri, and Talaromyces. ${ }^{40}$ These molds survive commercial heat pasteurization treatment, usually applied to fruits and fruit products because of the presence of heat resistant ascospores. ${ }^{41}$ Heat resistance has been reported to depend upon the fruit product. The report stipulates that as the concentration of sugar increases, heat resistance in microorganisms also increases.

The findings in this current work are noteworthy. Elucidating the importance of carboxylic acids and their products in pharmaceutics depend on the chemical nature of the functional group. Natural food components; typically, the acids existing in fruits and vegetables are found to function as acidulants, preservatives, emulsifiers, antioxidants, or flavors in an extensive variety of foodstuffs for human consumption. ${ }^{42,43}$ In addition, the extent and composition of organic acids existent in foodstuffs offer pertinent gen for fermentation processes scrutiny as well as regulate activities such as; the production, storage, and delivery phases or detect potential adulteration actions. Research report by Kalgutkar \& Daniels ${ }^{27}$ indicates that, in pharmaceuticals, carboxylic acids play important role as solubilizers, as well as development of prodrug or bioprecursor, most especially drugs from antihypertensive, antithrobotic, or antiviral categories. Carboxylic acid-containing medications exhibit a key function in the therapeutic management of ache and ailments and are applicable as constituents in cosmetics. A category of organic acids essentially involved in the cosmetic arena has been reported to be the alpha hydroxy acids (AHAs). ${ }^{42}$ Salehi et al., ${ }^{11}$ reported that oils from and extracts plants have been used as medical antiseptics and wound healing agents, food preservatives, and flavorings.

Previous research by Cerdeiras et al., ${ }^{44}$ shown that the compound, $11-O-(6$ '-O-acetyl- $\beta$-D-glucopyranosyl)-stearic acid as the key antibacterial component of aerial part of the plant Ibicella lutea. The fatty acid derivative found to be active against Escherichia coli, Pseudomonas aeruginosa, Bacillus subtilis and Staphylococcus aureus with MIC value of $9 \mu \mathrm{g} / \mathrm{ml}$ against $S$. aureus. Another research group $^{45}$ described the antibacterial activity of linoleic and oleic acids isolated from the leaves of Helichrysum pedunculatum. The team reported that the two acids inhibited the growth of Gram-positive B. subtilis, Micrococcus kristinae and $S$. aureus whilst linoleic acid showed activity against Bacillus cereus and Bacillus pumilis. They reported that both acids exhibited no activity against Gram-negative Enterobacter cloacae, E. coli, K. pneumoniae, P. aeruginosa and Serratia marcescens.

The PEG-Compound G ointment exhibited growth inhibitory activity against all the test microorganisms at varying concentrations (Figure 6). There was a significant difference in diameter zones of inhibition $(\mathrm{P}<0.05)$ when the concentration augmented from 2.5 to 5 $\mathrm{mg} / \mathrm{g}$. Comparable trends were observed when the ointment amount was raised upward to $20 \mathrm{mg} / \mathrm{g}$ indicating dose dependence activity of the PEG-Compound G ointment against the test microorganisms. It 
was further observed that the PEG-Compound G ointment exhibited substantial inhibition against all the test microorganisms at the various concentrations compared to the unformulated compound. This could be attributed to enhanced exposure and easy contact of the active compound to the microorganisms by the delivery vehicle. The MIC values determined for PEG-Compound $\mathrm{G}$ ointment were relatively low compared with the pure Compound $\mathrm{G}$ alone (Table 3). MBC and MFC for the formulated Compound G ointment were not detected up to a concentration of $40 \mathrm{mg} / \mathrm{g}$. In these contemporary eras, many substantial efforts have been applied to use the potentials of lipidbased drug delivery systems (LBBDS), as it affords the appropriate resources of target precision in addition to time controlled distribution of drugs as well as bioactive agents. ${ }^{46,47}$ Poorly lipophilic medicines are thought provoking for the formulation researchers regarding solubility and bioavailability. Lipid-based drug delivery systems, including PEG systems have revealed greater reliant properties; hence have attracted a lot of attention. Additionally, LBBDS seemed to have taken the lead due to noticeable gains of higher degree of biocompatibility and adaptability. Commercially, LBBDS have been reported to be sustainable in formulating pharmaceuticals for topical, oral, pulmonary as well as direct drug injection. ${ }^{48}$ Lipid formulations can be modified in copious methods to meet a wide range of product desires vis-à-vis the ailment state, path of delivery, product stability, toxicity, in addition to efficacy. Lipid-based transporters are innocuous and effectual and therefore demonstrated to be attractive agents for the preparation of pharmaceuticals, including vaccines, diagnostics, and nutraceuticals. ${ }^{49}$ Even though, the compound exhibited significant activity against the microorganism verified, we would not run away from the fact that in vivo and toxicity studies are essential in order to recommend the usage of the products mentioned in this current work.

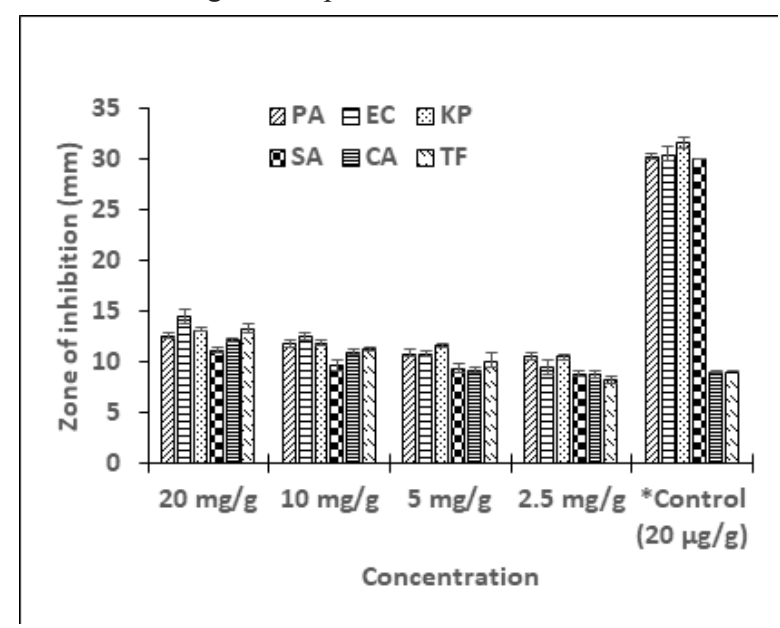

Figure 6 Growth inhibition activity of PEG-Compound G ointment on test bacteria and fungi.

$\mathrm{PA}, P$. aeruginosa; $\mathrm{EC}=\mathrm{E}$. coli; $\mathrm{KP}, \mathrm{K}$. pneumoniae; $\mathrm{SA}, \mathrm{S}$. aureus; $\mathrm{CA}=\mathrm{C}$. albicans; TV, T. flavus; *Control, Chloramphenicol; positive control for bacteria; Fluconazole, positive control for fungi.

\section{Conclusion}

The emergence and extent of antimicrobial resistance constitutes a major threat for human health, hence necessitated this research. We have accomplished for the first instance in isolating carboxylic fatty acid derivative from $\mathrm{n}$-hexane fraction of the leaf ethanol extract of $A$. barbadensis Miller and the structure characterized by means of FT-IR, ${ }^{1} \mathrm{H}$ and ${ }^{13} \mathrm{C}$ NMR spectroscopy. The compound and its PEG formulated ointment was tested and both exhibited anti-infective activity against some selected drug-resistant microorganisms, namely: E. coli, $K$. pneumoniae, P. aeruginosa, S. aureus C. albicans and T. flavus. Based on the aforementioned findings, the compound and the formulated ointment could be developed as wound and fugal infectious agents. These findings suggest that the isolated carboxylic acid precursor may be beneficial in the discovery of antibiotics highly potent against the selected microorganisms. Furthermore, it may add to the improvement of preservatives in the food industry. Lastly, it could be considered as new source of natural antibiotics in the pharmaceutical industry.

\section{Acknowledgements}

The authors would like to acknowledge the Director, Navrongo Health Research Centre (NHRC). The Head, Department of Applied Biology, C. K. Tedam University of Technology and Applied Sciences. We are also grateful to the Department of Chemistry, University of Ghana, Legon; Kwame Nkrumah University of Science and Technology, Kumasi; for permitting and supporting us for the NMR and IR spectral probe respectively.

\section{Conflicts of interest}

The authors declare that they have no known competing interests.

\section{Funding}

This research did not receive any specific grant from funding agencies in the public, commercial, or not-for-profit sectors.

\section{References}

1. Dabur R, Gupta A, Mandal TK, et al. Antimicrobial activity of some Indian medicinal plants. Afr $J$ Tradit Complement Altern Med. 2007;4(3):313-318

2. Mbaveng AT, Sandjo LP, Tankeo SB, et al. Antibacterial activity of nineteen selected natural products against multi-drug resistant Gramnegative phenotypes. SpringerPlus. 2015;4(1):823.

3. Mtunzi FM, Ejidike IP, Ledwaba I, et al. Solvent-solvent fractionations of Combretum erythrophyllum (Burch.) leave extract: Studies of their antibacterial, antifungal, antioxidant and cytotoxicity potentials. Asian Pac J Trop Med. 2017;10(7):670-679.

4. Abiramasundari P, Priya V, Jeyanthi GP, et al. Evaluation of the antibacterial activity of Cocculus hirsutus. Hygeia. 2011;3(2):26-31.

5. Newman MJ, Frimpong E, Donkor ES, et al. Resistance to antimicrobial drugs in Ghana. Infect Drug Resist. 2011;4:215.

6. Cowan MM. Plant products as antimicrobial agents. Clin Microbiol Rev. 1999;12(4):564-582.

7. Salehi B, Zakaria ZA, Gyawali R, et al. Piper species: a comprehensive review on their phytochemistry, biological activities and applications. Molecules. 2019;24(7):1364

8. Mukherjee P, Nema N, Maity N, et al. Phytochemical and therapeutic profile of Aloe vera. J Nat Rem. 2013;14(1):1-26.

9. Guo X, Mei N. Aloe vera: A review of toxicity and adverse clinical effects. J Environ Sci Health, Part C: Environ Carcinog Ecotoxicol Rev. 2016;34(2):77-96

10. Lawrence R, Tripathi $\mathrm{P}$, Jeyakumar E. Isolation, purification and evaluation of antibacterial agents from Aloe vera. Braz J Microbiol. 2009;40(4):906-915

11. Salehi B, Albayrak S, Antolak H, et al. Aloe genus plants: from farm to food applications and phytopharmacotherapy. Int $J \mathrm{Mol}$ Sci. 2018;19(9):2843. 
12. Eshun K, He Q. Aloe vera: a valuable ingredient for the food, pharmaceutical and cosmetic industries - a review. Crit Rev Food Sci Nutr. 2004;44(2):91-96.

13. Olaleye M, Bello-Michael C. Comparative antimicrobial activities of Aloe vera gel and leaf. Afr J Biotechnol. 2005;4(12).

14. Raksha B, Pooja S, Babu S. Bioactive compounds and medicinal properties of Aloe vera L.: An update. J Plant Sci. 2014;2(3):102-107.

15. Tanaka M, Misawa E, Ito $\mathrm{Y}$, et al. Identification of five phytosterols from Aloe vera gel as anti-diabetic compounds. Biol Pharm Bull. 2006;29(7):1418-1422.

16. Donkor A-M, Donkor MN, Kuubabongnaa N. Evaluation of antiinfective potencies of formulated aloin A ointment and aloin A isolated from Aloe barbadensis Miller. BMC Chem. 2020;14(1):1-8.

17. Donkor A-M, Mosobil R, Suurbaar J. In vitro bacteriostatic and bactericidal activities of Senna alata, Ricinus communis and Lannea barteri extracts against wound and skin disease causing bacteria Journal of Analytical \& Pharmacentical Research. 2016;3(1):00046.

18. Suurbaar J, Mosobil R, Donkor A-M. Antibacterial and antifungal activities and phytochemical profile of leaf extract from different extractants of Ricinus communis against selected pathogens. BMC Res Notes. 2017;10(1):660.

19. Sacchi R, Addeo F, Paolillo L. ${ }^{1} \mathrm{H}$ and ${ }^{13} \mathrm{C}$ NMR of virgin olive oil. An overview. Magn Reson Chem. 1997;35(13):S133-S145.

20. Lucarini M, Durazzo A, Kiefer J, et al. Grape seeds: Chromatographic profile of fatty acids and phenolic compounds and qualitative analysis by FTIR-ATR spectroscopy. Foods. 2020;9(1):10.

21. Tarhan İ, Ismail AA, Kara H. Quantitative determination of free fatty acids in extra virgin olive oils by multivariate methods and Fourier transform infrared spectroscopy considering different absorption modes. Int J Food Prop. 2017;20(sup1):S790-S797.

22. da Silva HR, Quintella CM, Meira M. Separation and identification of functional groups of molecules responsible for fluorescence of biodiesel using FTIR spectroscopy and principal component analysis. J Braz Chem Soc. 2017;28(12):2348-2356.

23. Mahesar S, Kandhro AA, Khaskheli AR, et al. SB-ATR FTIR spectroscopic monitoring of free fatty acids in commercially available Nigella sativa (Kalonji) oil. J Spectrosc. 2014;2014.

24. Ayeleso TB, Matumba MG, Mukwevho E. Oleanolic acid and its derivatives: biological activities and therapeutic potential in chronic diseases. Molecules. 2017;22(11):1915.

25. Zhou L, Liu W, Xiong Z, et al. Different modes of inhibition for organic acids on polyphenoloxidase. Food Chem. 2016;199:439-446.

26. Chalmers R. Organic acids in man: Analytical Chemistry, Biochemistry and Diagnosis of the organic acidurias. Amsterdam: Springer Science \& Business Media; 2012.

27. Kalgutkar AS, Daniels JS. Carboxylic acids and their bioisosteres. In: Smith DA, editor. Metabolism, Pharmacokinetics and Toxicity of Functional Groups: Impact of Chemical Building Blocks on ADMET. Cambridge: The Royal Society of Chemistry; 2010:99-167.

28. Yoon BK, Jackman JA, Valle-González ER, et al. Antibacterial free fatty acids and monoglycerides: biological activities, experimental testing, and therapeutic applications. Int J Mol Sci. 2018;19(4):1114.

29. Won S-R, Hong M-J, Kim Y-M, et al. Oleic acid: an efficient inhibitor of glucosyltransferase. FEBS Lett. 2007;581(25):4999-5002.

30. Doughari J, Okafor B. Antimicrobial Activity of Senna alata Linn. East and Central African Journal of Pharmaceutical Sciences. 2007;10(1):17-21.
31. Masoumian M, Zandi M. Antimicrobial activity of some medicinal plant extracts against Multidrug Resistant Bacteria. Zahedan J Res Med Sci. 2017;19(11):e10080.

32. Ghannoum MA, Rice LB. Antifungal agents: mode of action, mechanisms of resistance, and correlation of these mechanisms with bacterial resistance. Clin Microbiol Rev. 1999;12(4):501-517.

33. White TC, Holleman S, Dy F, et al. Resistance mechanisms in clinical isolates of Candida albicans. Antimicrob Agents Chemother. 2002;46(6):1704-1713.

34. Odds FC, Brown AJ, Gow NA. Antifungal agents: mechanisms of action. Trends Microbiol. 2003;11(6):272-279.

35. Cowen L, Sanglard D, Howard S, et al. Mechanisms of antifungal drug resistance. Cold Spring Harb Perspect Med. 2014;5:a019752.

36. Hope WW, Tabernero L, Denning DW, et al. Molecular mechanisms of primary resistance to flucytosine in Candida albicans. Antimicrob Agents Chemother. 2004;48(11):4377-4386.

37. Mayer FL, Wilson D, Jacobsen ID, et al. Small but crucial: the novel small heat shock protein Hsp21 mediates stress adaptation and virulence in Candida albicans. PLoS One. 2012;7(6):e38584.

38. Fiori A, Van Dijck P. Potent synergistic effect of doxycycline with fluconazole against Candida albicans is mediated by interference with iron homeostasis. Antimicrob Agents Chemother. 2012;56(7):37853796.

39. Morio F, Loge C, Besse B, et al. Screening for amino acid substitutions in the Candida albicans Erg11 protein of azole-susceptible and azoleresistant clinical isolates: new substitutions and a review of the literature. Diagn Microbiol Infect Dis. 2010;66(4):373-384.

40. Tournas V, Heeres J, Burgess L. Moulds and yeasts in fruit salads and fruit juices. Food Microbiol. 2006;23(7):684-688.

41. Lawlor KA, Schuman JD, Simpson PG, et al. Microbiological spoilage of beverages. In Compendium of the Microbiological Spoilage of Foods and Beverages. In: Sperber WH, Doyle MP, editors. Food Microbiology and Food Safety. New York: Springer Science and Business Media; 2009:245-284.

42. Lukic M, Pantelic I, Savic S. An overview of novel surfactants for formulation of cosmetics with certain emphasis on acidic active substances. Tenside Surf Det. 2016;53(1):7-19.

43. Yu RJ, Van Scott EJ. Alpha-hydroxyacids and carboxylic acids. J Cosmet Dermatol. 2004;3(2):76-87.

44. Cerdeiras M, Fernández J, Soubes $\mathrm{M}$, et al. A new antibacterial compound from Ibicella lutea. J Ethnopharmacol. 2000;73(3):521-525.

45. McGaw L, Jäger A, Van Staden J. Antibacterial effects of fatty acids and related compounds from plants. S Afr J Bot. 2002;68(4):417-423.

46. Brigger I, Dubernet C, Couvreur P. Nanoparticles in cancer therapy and diagnosis. Adv. Drug Delivery Rev. 2012;64:24-36.

47. Panyam J, Labhasetwar V. Biodegradable nanoparticles for drug and gene delivery to cells and tissue. Adv Drug Delivery Rev. 2003;55(3):329347 .

48. Shrestha H, Bala R, Arora S. Lipid-based drug delivery systems. Journal of Pharmaceutics. 2014;2014(Article ID 801820):1-10.

49. Pouton CW, Porter CJ. Formulation of lipid-based delivery systems for oral administration: materials, methods and strategies. Adv Drug Delivery Rev. 2008;60(6):625-637. 